\title{
OS DESAFIOS NA CAPACITAÇÃO PEDAGÓGICA DE TUTORES NA MODALIDADE DE ENSINO A DISTÂNCIA
}

\author{
THE CHALLENGES IN THE PEDAGOGICAL TRAINING OF TUTORS IN THE MODE OF \\ DISTANCE TEACHING
}

\begin{abstract}
Patrícia Maria Medeiros de Andrade
Universty Sustainable Development-Uds, Asunción, Paraguai. E-mail: patriciamaria.as@hotmail.com
\end{abstract}

DOI: https://doi.org/10.46550/amormundi.v2i4.105

Recebido em: 24.05.2021

Aceito em: 30.07.2021

\begin{abstract}
Resumo: $O$ presente estudo teve como objetivo principal investigar os desafios na capacitação pedagógica dos tutores na modalidade $\mathrm{EaD}$. A proposta do trabalho consistiu em compreender o papel do tutor no processo de aprendizagem e como ele é adquirido. A metodologia baseou-se em uma pesquisa exploratória, documental e predominantemente qualitativa realizando pesquisa de campo, a pesquisa será de método misto (qualitativo e quantitativo). A populaçáo do estudo foi composta por um tutor do polo de ensino superior a distância localizada em Manaus e a coleta de dados foi realizada através de um questionário semiestruturado. Ao fim da investigação conclui-se que o ensino a distância é desafiador e que apresenta pontos positivos e negativos, cabendo ao tutor realizar o acompanhamento, orientar e estimular os educandos. Gerando e difundindo conhecimentos em alto grau com senso de responsabilidade, tanto para com o sistema ao qual se está vinculado, quanto para o enriquecimento (em amplo sentido) da instituição que se representa física ou virtualmente
\end{abstract}

Palavras-chave: Capacitação. Educação a Distância. Tutores.

Abstract: The main objective of this study was to investigate the challenges in the pedagogical training of tutors in the EaD modality. The purpose of the work was to understand the role of the tutor in the learning process and how it is acquired. The methodology was based on an exploratory, documentary and predominantly qualitative research conducting field research, the research will be mixed method (qualitative and quantitative). The study population consisted of a tutor from the distance higher education pole located in Manaus and data collection was carried out through a semi-structured questionnaire. At the end of the investigation, it is concluded that distance learning is challenging and that it has positive and negative points, and it is up to the tutor to monitor, guide and encourage students. Generating and disseminating knowledge to a high degree with a sense of responsibility, both towards the system to which it is linked and towards.

Keywords: Training. Distance Education. Tutors.

\section{Introduçáo}

Ste artigo é resultado de uma dissertação de mestrado com o título "Ensino Superior a
Distância: Desafios na Capacitação Pedagógica de Tutores na Modalidade de Ensino a Distância”. O objetivo geral desse estudo foi investigar os desafios na capacitação pedagógica dos tutores na modalidade EaD. A proposta do trabalho consistiu em compreender o papel do 
tutor no processo de aprendizagem e como ele é adquirido.

Em sociedade, nos deparamos com uma competitividade acirrada em busca de formação e conhecimento o que torna o tempo algo precioso a ser aproveitado, de forma que o indivíduo possa ser participativo no processo voltado ao ensino e aprendizagem. Partindo desse pressuposto, a relevância dos cursos superiores a distância apresenta-se como um segmento de significativa importância no desenvolvimento do acesso ao conhecimento formal.

O ensino a distância acaba ofertando vantagens de modo a democratizar a educação, rompendo as barreiras geográficas, sociais, culturais e econômicas, promovendo de forma integra uma formação sistemática do conhecimento.

Segundo Júnior et al. (2015) do ponto de vista social, o acesso das pessoas que possuem alguma dificuldade de inserção no ensino superior, se dá muitas das vezes por residirem distantes das universidades, indisponibilidade de tempo ou horário incompatível com as aulas presenciais, demandando maior tempo do aluno em um curso superior presencial.

O ensino a distância acaba oferecendo vantagens de modo a democratizar a educação, rompendo as barreiras geográficas, sociais, culturais e econômicas, promovendo de forma integra uma formação sistemática do conhecimento.

$\mathrm{Na}$ vertente econômica podemos dizer que o avanço tecnológico, como por exemplo a expansão e estabilização da rede mundial de comunicação, internet, tem proporcionado grandes avanços significativos na educaçáo como um todo, onde os alunos possuem maior liberdade em desenvolver conhecimento adquirido sem necessitar apresentar-se em período integral diante de seu professor, viabilizando economia de transporte para ambos os lados.

$\mathrm{Na}$ instituição há economia nas instalações elétricas e hidráulicas, e de modo geral acaba se tornando uma forma mais segura de educação pois o ensinamento é obtido por via on-line, através de equipamentos periféricos portáteis que são acessados de qualquer lugar que a pessoa julgue como seguro a ela (MENDONÇA, 2016).

Observando a expansão do ensino a distância no Brasil, porém, ainda com certa resistência por parte de alguns discentes mais tradicionais quanto ao ensino presencial. E ainda, considerando que o aumento na demanda e na oferta por essa modalidade de ensino implica em fornecer serviços com ainda mais qualidade, além de aprendizagem efetiva para uma educação emancipadora e que siga em constante progresso, atualização, aperfeiçoamento, tanto por parte dos alunos, quanto por parte do tutor, foco desta pesquisa.

Portanto se faz necessário realizar um estudo para maior compreensão do desenvolvimento da docência nesta modalidade de ensino. Para esse entendimento há necessidade de análise sobre os modos pelos quais os modelos de docência virtual contribuem no cotidiano educacional. Assim como procurar compreender as dificuldades, desafios, facilidades e as estratégias que a tutoria virtual pode exercer nas intuiçôes participantes, que são os saberes docentes para essa modalidade, assim como a forma em que o docente virtual adquire esses saberes e os percebe.

Essa pesquisa realizou-se através de análise investigativa acerca dos desafios na Capacitação Pedagógica dos Tutores na Modalidade de Ensino à Distância $(\mathrm{EaD})$ em uma instituição de Ensino Superior da Cidade de Manaus - AM. Aplicou-se a investigação por meio de entrevistas e analisouse os resultados acadêmicos para a comunidade, averiguando as competências e habilidades de tutores envolvidos, buscando sugerir capacitaçóes adequadas as melhorias do serviço. 


\section{Metodologia}

A metodologia deste projeto deu-se como caráter qualitativo e quantitativo, com aplicação de questionário, ensino e aprendizagem como forma de procedimentos, sendo um fator primordial objetivando ampliar o desenvolvimento no que refere aos métodos e técnicas da pesquisa indispensável ao conhecimento e abordagens científicas. É importante salientar que grande parte dos conteúdos analisados são de natureza qualitativa, sendo significativos para compor a interpretação direta condizente na realizaçáo do projeto de pesquisa.

Como critérios de inclusão foram coletados dados de participantes de ambos os sexos, tutores qualificados para $\mathrm{EaD}$, com idade acima dos 18 anos, que concordaram e assinaram o TCLE. A investigação ocorreu em três etapas.

Desta forma, destacamos a grande contribuição metodológica na escolha voltada a uma pesquisa bibliográfica assim como seguimento qualitativo como prática eficaz na reflexão em leituras de artigos, sites e literaturas relacionados ao exercício profissional e desafio de tutores em educação a distância, constituindo um fator elementar no processo de formação acadêmica de alunos inseridos nas modalidades em EaD.

Quanto a pesquisa in loco, nesta fase procedeu-se com a investigação em campo para averiguação das percepçóes acerca dos desafios na capacitação pedagógica dos tutores em Ensino a Distância em uma instituição de ensino superior em Manaus, Amazonas

No primeiro momento, houve visita informal, quando ocorreu apresentação do tema, objetivo e justificativas do projeto. Posteriormente foi entregue pela pesquisadora a carta de consentimento esclarecido na qual está em anexo I, com objetivo de esclarecer o motivo da pesquisa e oficializando os procedimentos para início efetivo da investigação, com os tutores que gentilmente se disponibilizaram a colaborar.

A este respeito, Marconi e Lakatos (1996, p. 88) conceituam o questionário estruturado como uma "[...] série ordenada de perguntas, respondidas por escrito sem a presença do pesquisador". Uma das maiores vantagens em utilizar questionário tem relação com a padronização das questôes, auxiliando na interpretação uniforme dos participantes, otimizando tanto compilação quanto analogia de seu produto.

\subsection{Primeira fase - exploratória}

A primeira fase iniciou-se com pesquisa exploratória em obras literárias físicas e disponíveis virtualmente, além de acesso a sites de instituiçôes oficias para averiguação de dados que possam, após minuciosa análise pela pesquisadora, contribuir para o desenvolvimento desta pesquisa. Os modelos teóricos e obras já apresentadas a respeito, contribuem de forma grandiosa para a contextualização do assunto. Da mesma forma se almeja que esta pesquisa auxilie em reflexóes futuras.

Essa fase alinhou na classificação de conceitos, esclarecimento de posicionamentos de cada autor sobre o tema, auxilia no posicionamento científico da pesquisadora, congruente nos resultados desta pesquisa em si semelhantes que foram realizadas. Como método para coletar os dados foram utilizados: questionário, entrevistas e visitas in loco para troca de informaçóes informais. 


\subsection{Segunda fase - pesquisa de campo}

Elaborou-se e aplicou-se os instrumentos de coletas de dados, ou seja, os questionários e as entrevistas aos sujeitos da pesquisa. A aplicabilidade e a acolhida dos questionários por parte dos entrevistados, auxiliaram bastante na concepção de parecer coerente com os estudos teóricos desenvolvidos ao longo deste trabalho.

\subsection{Terceira fase - procedimentos e análise das informaçóes}

As análises se deram de forma qualitativa, que visa observação mais direta, pois utilizouse do ambiente natural como fonte direta para coleta de dados, onde a pesquisadora se faz essencial para essa coleta de informaçóes. Tratando-se de uma pesquisa descritiva, com foco em descrever fenômenos encontrados no local de sua observação, assim, os resultados serão expressos em forma de transcrição das entrevistas e de narrativas, etc.

\section{Resultados e discussóes}

Após todas as explanaçôes apontadas neste trabalho, ressalta-se que o foco da pesquisa é tutor no universo do ensino a distância em seus desafios, demanda por capacitação constante, contribuição para o desenvolvimento social e cultural.

Ao responder o questionário amostra, embasado nos autores consultados anteriormente ao trabalho em campo, podemos observar que as respostas obtidas, alcançam o objetivo da pesquisa, respondendo as questóes norteadoras, atendendo aos objetivos aqui colocados.

A entrevista, no entanto, foi aplicada somente a uma tutora. Sendo os sujeitos da pesquisa da Instituição de Ensino Superior selecionada para este trabalho, localizada em Manaus, Amazonas, a tutora amostra da pesquisa. O questionário, igualmente, foi aplicado a apenas 01 tutora, como amostra da pesquisa.

Assim ocorreu, pois, respeitando o estado de isolamento social recomendado durante a pandemia de Sars Cov - 02, e ainda, observando os critérios da pesquisa com observação direta dos potenciais entrevistados, algo inviável durante a quarentena de Covid-19. Optou-se por manter apenas a única amostra alcançada nesta pesquisa, componente deste trabalho, em Apêndices.

O tutor que se obteve acesso para aplicação do questionário validado para esta pesquisa, espontaneamente forneceu as seguintes afirmativas:

$\mathrm{Na}$ questão de número, 1 - Você tem dificuldades em transmitir conhecimento no modelo de educação em EaD? Sua resposta (x) não, demostrando assim que neste caso em particular, há familiaridade com informática, interação virtual e domínio do conteúdo de sua responsabilidade a ser mediado.

A resposta de número 2 - Material didático e mídia utilizadas nas aulas de $\mathrm{EaD}$, são compreendidas de maneira satisfatória? (x) sim, aparentemente confirma fácil assimilação por parte dos discentes, baseado na baixa frequência de indagaçóes registradas em fóruns abertos e em acesso privado também, por outro lado, pode ser uma ilusão.

Os alunos poderiam estar tão confusos a ponto de não haverem se habituado a registrar duvidas pela plataforma, porém essa sugestão fica fora de questão quando da necessidade de um 
ou outro encontro presencial para acertos de alguma assinatura, avaliação presencial, etc. Onde os presentes mantêm a postura de fácil assimilação do conteúdo do portal.

Respondendo a questão de número 3 - O tutor deve promover as discussôes ou criar fóruns que, através da temática e ou do recurso utilizado, gere uma interatividade e provoque o desenvolvimento de uma autonomia entre todos os participantes. Você tem o retorno (feedback) dessa atividade de modo satisfatório? A tutora de nossa amostra com seu sim, (x) sim (Aulas Inaugurais para apresentar o aluno na utilização da plataforma), afirma que há interesse da parte dos alunos em interagir com o tutor apesar da facilidade em percorrer o ambiente virtual entre as atividades propostas ao longo do semestre, em especial em seu início, onde ambos estabelecem no primeiro contato, as bases sociais para continuidade harmônica de suas comunicações.

$\mathrm{Na}$ questão 4, onde indagou-se sobre - Como você avalia a articulação da equipe pedagógica (professores, coordenadores acadêmicos e tutores) de seu curso? (x) articulada, é a resposta que apresenta o pré atendimento ao discente em aprendizagem, e, portanto, suscetível a reproduzir, inclusive no ambiente virtual, a atenção que recebe de seu tutor. Ou seja, o Tratamento e nível de interação do tutor em atividade, mesmo através de sua expressão digitada em respostas simples, também é reflexo da interação com a equipe por trás das câmeras, no polo da instituição sede a qual é vinculado seu ofício docente de mediação.

Ao ser questionada sobre, 5, Como você classifica a interação entre alunos, orientador acadêmico, equipe técnica e tutores ao longo do curso? Com a resposta "( $x$ ) adequada”, a entrevistada demonstra perceber a interação de forma geral dentro das expectativas básicas para o bom desempenho das atividades em $\mathrm{EaD}$.

Em 6 - Como você avalia o processo de orientação e acompanhamento dos tutores do polo, ao longo do curso? Sua resposta pela primeira vez não foi a mais positiva: (x) razoavelmente adequada, o que representa um ponto de atenção para que medidas de observação e orientação interna sejam tomadas em aspecto contingencial.

$\mathrm{Na}$ avaliação da atuação do coordenador do polo no atendimento e/ou esclarecimento acadêmico ao estudante? A pergunta 7 apresenta esta interação registrada: (x) razoavelmente adequada, o que representa um ponto de atenção para que medidas de observação e orientação interna sejam tomadas em aspecto contingencial.

Na questão de número 8, - Como você avalia a atuação do suporte técnico do curso? Com a escolha de (x) razoavelmente adequada (Poderia melhorar com utilizaçáo de computadores) obtemos novamente um ponto de atenção para que medidas de observação e orientação interna sejam tomadas em aspecto contingencial. Inclusive com a análise financeira orçamentária, visando provisionar recursos para a aquisição de máquinas conforme planejamento adequado.

A questão número 9, - Você como tutor percebe a satisfação ou insatisfação na disciplina e no curso? É um coringa que permite margem para manifestação livre do entrevistado ao apresentar em mais detalhes sua satisfação ou mesmo insatisfação de seus discentes. Sua resposta foi apenas $(\mathrm{x})$ sim, sem maiores aprofundamentos espontâneos.

Fechando o questionário com a décima questão, 10 - Você conhece os fundamentos e metodologias da Educação a Distância / Dominar técnicas pedagógicas de Tutoria, assim como o conteúdo do curso, o projeto pedagógico, o calendário etc. /as disciplinas ministradas. Almejouse extrair da pessoa entrevistada, pistas que indiquem através inclusive de sua comunicação não 
verbal, elementos que confirmem se na realidade, o trabalho de tutoria é realizado mediante um processo básico de integração, capacitação, reciclagem, etc. Ou se apenas ocorre a nomeação de alguém "disponível" para representar o papel de mediação quanto convenientemente exigido por qualquer das partes interessadas. Sua resposta firme, $(\mathrm{x})$ sim, transmitiu a segurança necessária para uma boa avaliação de todo o conteúdo abordado sobre este tema.

Assim, o objetivo geral é atingido com uma investigação de desafios na capacitação pedagógica dos tutores na modalidade do Ensino a Distância, pautada no histórico da educação que continua em evolução através do desenvolvimento de outras modalidades de ensino, como $\mathrm{EaD}$, ainda com muitas lacunas, porém em fase de plena simbiose com os novos estudantes de todo o mundo.

Os dados não precisaram ser tabulados, bastando sua apresentação e interpretação embasado a luz dos teóricos com os resultados coletados.

Em Martins (2010), a figura do tutor se destaca na modalidade a distância, na medida em que seu papel acadêmico tem como compromisso possibilitar ao aluno o acesso ao conhecimento, a reflexão e ao saber.

Nesse caso o mediador, deve estar atento, de modo a que todos se apropriem do conhecimento e, consequentemente, alcancem as funçóes superiores da consciência, pois é a aprendizagem que vai determinar o desenvolvimento. $\mathrm{O}$ mediador, portanto, atua na zona de desenvolvimento proximal do sujeito em que, por meio de intervençốes intencionais, possibilita a aquisição dos conhecimentos sistematizados (KAMINSKI, 2015).

Sobre o tutor ensinar enquanto aprende, considerando o dinamismo e flexibilidade do conhecimento que não é linear.

O tutor representa um verdadeiro elo entre o discente e o conhecimento, mas também é o mediador entre a ferramenta e a instituição.

Em Pacheco (2015), encontramos como pontos fortes dos tutores a distância a disponibilidade para o esclarecimento de dúvidas, uma vez que o conteúdo disponibilizado, pois claro e objetivo que seja, eventualmente causa hesitação no usuário ainda não adaptado à plataformas de ensino EaD; Possuem respostas rápidas via e-mail: muitas das perguntas realizadas pelos alunos, já fazem parte de um banco de dados frequentemente utilizado nessas situaçóes em que perguntas comuns já possuem respostas prontas com fácil acesso ao gerenciador das respostas, também conhecido como FAQ, do inglês "Frequently Asked Questions";

São determinados, coerentes, agem com clareza nas respostas que fornecem e igualmente nas solicitaçóes que emitem; possuem facilidade na comunicação; monitoram e auxiliam no desenvolvimento de trabalhos; flexibilizam seu atendimento aos alunos; tem disponibilidade no horário de atendimento; são prestativos; repassam informações complementares das aulas; desenvolvem o conteúdo das aulas; muito atenciosos, tiram dúvidas em momentos alternativos (finais de semana por exemplo).

São proativos; sempre lembram os alunos sobre os prazos das atividades, detalham o conteúdo, tem agilidade nas correções das atividades ao máximo possível; são exigentes, expandindo o assunto abordado nas aulas; prestam atenção individual de acordo com a dificuldade de compreensão de cada aluno; possibilitam a interação com o tutor mesmo sem sair de casa.

$\mathrm{O}$ autor em seguida destaca alguns pontos fracos a serem trabalhados e melhorados: 
os tutores a distância demoram nas respostas; são mais distantes na comunicaçáo na hora de tirar dúvidas; apresentam dificuldade de entrosamento; falta de interesse e comunicação entre professores e tutores; falta de respostas e esclarecimento em determinados assuntos, dificuldades na compreensão dos questionamentos;

Falta de um suporte adequado; falta de integração com os polos presenciais; descaso na ajuda com atividades avaliativas; falta de conhecimento nas disciplinas; comunicação ineficaz; respostas impessoais e generalizadas; falta de contato pessoal; dificuldades de expressar como devem ser feitas as atividades, respostas vagas, muito teóricos.

As vezes o tutor que orientou as atividades não é o mesmo que as corrige, não está disponível quando os alunos precisam esclarecer dúvidas; falta de conhecimento da matéria; pelo fato do portal apresentar problemas de conexão, dificulta o contato com o tutor, falta a de comunicação com o tutor presencial.

Quanto aos resultados da pesquisa, a pesquisadora ainda constatou que em geral alguns tutores em EaD obtém melhores resultados que outros no enfrentamento de seus desafios

Lembrando brevemente que o arranjo físico a partir de onde se realiza o trabalho de tutoria, tende a representar fator de influência no trabalho de mediação. Ao apresentar-se no ambiente escolar, o docente responsável pela tutoria precisa dedicar-se ao seu trabalho específico sem outras interferências, conversas paralelas, nem mesmo ajudinhas em outros serviços na instituição.

Por outro lado, o trabalho de tutoria em formato de home office, ou seja, a partir da residência do tutor ou de outros locais que não sejam o polo educacional ao qual está relacionado, deve garantir os meios básicos para trabalhar. Isso envolve a começar arranjo físico adequado, iluminado, seguro, seco, relativamente confortável, com acesso ao ambiente virtual de aprendizagem - AVA, internet de boa qualidade, silencio que auxilie em sua concentração, entre outros.

Alguns tutores conseguem avançar mais nas suas atividades e outros conseguem menos, evidenciando que isso ocorre devido as particularidades que compóem o seu trabalho, sendo que a demanda por outros saberes ou outros espaços não dependem com exclusividade das unidades escolares, pois, as aulas também acontecem em espaços diferenciados, dificultando ou acelerando o avanço dos alunos no processo ensino-aprendizagem, de acordo com a situaçáo que cada um vivencia por trás da tela do computador. Estabelece-se em um processo educativo que favorece a horizontalidade, sem desconsiderar os saberes historicamente acumulados (IVASHITA; VIEIRA, 2009).

Que ainda hoje em dia a maioria dos professores não dão a devida atenção à modalidade de EaD. Geralmente isto ocorre por causa da tendência em estarem mais empenhados com a educação presencial tradicional. Porém, ao agir assim, os mesmos perdem grandes oportunidades em desenvolver mais e melhor a educação a distância do nosso país, além disso poderiam incentivar a construção e o desenvolvimento de novos negócios com mais atitude. Como afirma Doria (2000), através da Educação à Distância “[...] o conhecimento passou a morar na ponta dos dedos de qualquer cidadão".

No decorrer deste trabalho, observou-se que assim como na literatura consultada, bem como em campo, o tutor recebe diversas denominaçóes variantes de seu trabalho desempenhado 
na mediação da aprendizagem em $\mathrm{EaD}$. O tutor tem recebido diversas denominaçóes: orientador, articulador e facilitador da aprendizagem, motivador, estimulador, potencializador, tutororientador, tutor-professor, e até mesmo animador de rede (OLIVEIRA, 2013).

Esse profissional ainda assume funções que não parecem da sua competência, mas sim de outros profissionais. Também, ao contrário, atividades e tarefas que pensava serem da sua alçada deixaram de ser cumpridas ou serem assumidas. Dessa forma, são as funçóes que o Tutor desenvolve em cursos de $\mathrm{EaD}$ que arquitetam o seu papel e colaboram para o alcance dos objetivos desses cursos (OLIVEIRA, 2013).

A variante de atividades desempenhadas em ambiente escolar presencial e virtual, vão bem além de responder questóes frequentes relativas a disciplina ministrada ou tutoriais de acesso a cada parte do AVA. É comum que seus procedimentos atendam a um determinado nível de experiência ou mesmo conhecimento teórico acerca de alguma formação acadêmica precedente ao seu trabalho em tutoria. Mas, qual a formação necessária a esse profissional?

De acordo com Lélis (2011) o tutor deve obter uma formação condizente com as suas atribuiçôes a serem realizadas, fazendo-se necessário a qualificação acadêmica no mínimo com pós-graduação, ter cursos específicos na área da Educação a Distância e experiências comprovadas. Isso deve ser o mínimo para iniciar seu papel no desenvolvimento de competências através das ferramentas que a $\mathrm{EaD}$ disponibiliza ao diálogo, interação, produção de conhecimento a se debater e compartilhar. Mas a formação do Tutor não se encerra aí, devendo o Sistema de Gestão do Curso estar atento e cuidar da formação continuada desse profissional.

Para Silva Junior et. al (2015) o papel do tutor é como de um ator importante nos processos de ensino-aprendizagem; no papel de mediação do conhecimento; possui papel estratégico junto aos professores e aprendentes, evitando assim as lacunas no processo ensinoaprendizagem e ampliando o debate e a socialização do conhecimento.

De acordo com Munhoz (2014), o destaque a um enfoque didático e pedagógico é benéfico em todos os sentidos. Trata-se da elaboração de tutoriais que periodicamente atualizados, forneçam liberdade tanto para o aluno quanto para o tutor, experimentar a compreensão prévia do passo a passo dos mecanismos de acesso e elaboração de ideias dentro do ambiente virtual de aprendizagem, antes de mecanicamente acionar o tutor para respostas óbvias, ou ainda de interesse coletivo, mas que ficam em nível particular quando realizadas fora de contexto propício ao debate coletivo em fóruns de alunos, por exemplo.

É necessário transmitir ao professor, integralmente, o que ele pode fazer com a tecnologia, ensinando que pode lhe dar condiçôes de trabalhar de forma diferenciada com a mediação tecnológica (MUNHOZ, 2014).

É preciso que a instituição de ensino e seus tutores enxerguem não apenas a necessidade de processos de qualificação, baseados em elementos básicos necessários à formação (leitura, compreensão de textos, matemática elementar e conhecimento tecnológico); é essencial que vejam também a necessidade de assumir a sua parte, oferecendo ao aluno o melhor atendimento possível.

Nem sempre quem desenvolve os cursos e seu projeto instrucional é quem acompanha o desenvolvimento do aluno (BELLONI, 1999). O profissional tem de conhecer profundamente o tema para poder utilizar o material de forma competente (MUNHOZ, 2014). 
$\mathrm{Na}$ maior parte do tempo, porém, os problemas ficam ocultos nas atitudes dos próprios alunos. No ambiente virtual de aprendizagem, é exigida a sua transformação em um elemento participante, incentivador e orientador, capaz $\mathrm{d}$ desenvolver um controle de aprendizagem, no sentido de melhor orientar o aluno, de forma individual, seja na busca de conteúdo, como também nas formas de desenvolver a perspectiva de aprender a aprender (MUNHOZ, 2014).

É o tutor quem deve encarar o aluno como uma pedra bruta que chega às suas mãos e que pode ser moldada de acordo com características como desenvolver a aprendizagem ativamente, de forma crítica, criativa e inovadora (MUNHOZ, 2014).

Deve-se considerar que aprendizagem ocorre em nível individual, dependente de um trabalho extensivo desenvolvido pelo aluno, com o apoio das redes sociais e a orientação de uma atividade de acompanhamento (MUNHOZ, 2014).

O desenvolvimento de trabalhos em ambientes digitais, com tecnologia de ponta, nos quais a mediação tecnológica é uma necessidade imperativa. A didática é o principal instrumento do professor: é o que define a qualidade do processo de ensino que ele pode oferecer ao seu aluno. Incentivar a participação, motivar o aluno, induzi-lo a refletir, saber orientá-lo na busca de objetivos, demonstrar comprometimento com a atividade de aprendizagem, desenvolver um bom processo de comunicação - Essas são algumas das características importantes do professor (MUNHOZ, 2014)

É imperativo ressaltar que a autoaprendizagem não representa necessariamente que o educando estará desassistido na construção do conhecimento, posto que os cursos a distância majoritariamente contam com a atuação de professores, tutores e diversos outros profissionais na nobre missão de desenvolver a mediação pedagógica (SILVA JUNIOR et al., 2015).

Além disso, criar meios e formatos potencialmente facilitadores da transmissão de determinados conteúdos e informaçóes. Precisa estar atento às novas e principais tendências em educação on-line, de modo a incentivar o engajamento de atuais e novos alunos na modalidade de ensino a distância

Em acordo com Silva Junior et. al (2015) que afirma em termos gerais a compreensão da tutoria em EaD como ação orientadora e pedagógica global. Pois ultrapassa sempre abrangendo muito mais do que apenas o domínio sobre a disciplina ministrada sobre o curso em vigência. É ação multidisciplinar em colaboração com várias outras atividades relacionadas ao desempenho de ambos os participantes no processo de ensino-aprendizagem total.

Estima-se que os resultados deste trabalho de pesquisa, além de efetivamente relevantes, proporcionem a trabalhos futuros, mais oportunidades de produção do conhecimento e sua difusão para cada vez mais pessoas. Que culmine não ao alcance de alguma meta específica, mas seja sempre meio disponível a continuidade perene do processo de desenvolvimento didático e pedagógico das pessoas que o acessarem. 
As ideias pedagógicas utilizadas, junto com a teoria de aprendizagem (o conectivismo), mostraram uma capacidade de sinergia que permitiu considerar o objetivo proposto como atingido.

Chegando nas consideraçôes finais nos deparamos com a realidade de que ainda há muito para se desenvolver sobre esse assunto. Porém seria irrelevante e presunção a tentativa de esgotar o tema apenas com esta pesquisa. E ainda que se fizesse, rapidamente as mudanças pelas quais o mundo vem passando, tornam tudo obsoleto.

Fortalecer o debate sobre os desafios na educação a distância é algo natural para o meio acadêmico náo apenas de parte dos gestores das instituiçóes de ensino em busca de profissionais capacitados para gerir esta modalidade. A capacitação de tutores em $\mathrm{EaD}$ é uma exigência por parte dos alunos que acessam as plataformas de ensino, dos próprios docentes em busca de fornecer melhores serviços e obter assim, melhores resultados em suas carreiras.

Desse modo, sugere-se como futuras investigações, estudo comparativo entre instituiçóes de ensino com a modalidade $\mathrm{EaD}$, em relação aos resultados qualitativos e quantitativos decorrentes da dinâmica de seus tutores com as partes interessadas as quais interagem: alunos, gestores, equipes de tecnologia da informação, fontes externas, etc.

Que se organize o diálogo em pelo menos dois momentos ao início da pesquisa e ao término com aplicação de tutorial dos processos de $\mathrm{EaD}$, devidamente adequados à realidade das instituiçóes em questão.

Compilaçáo de dados coletados sobre o aproveitamento do tempo on line, como taxa de resposta aos alunos, tempo disponibilizado para capacitação em EaD como tutor, outras capacitaçóes inerentes a função como informática e especialização na disciplina gerida.

\section{Referências}

BELLONI, M. Luiza. Educação a distância. São Paulo: Editores Associados, 1999.

DÓRIA, Daniela. Tecnicismo: uma página virada na história da EaD? setembro/2000.

Disponível em: <http://alvoradaseis.blogspot.com/2008/04/tecnicismo-uma-pgina-virada-nahistria.html>. Acesso em: 02/04/2020.

IVASHITA, Simone Burioli; VIEIRA, Renata de Almeida. Os antecedentes do Manifesto dos Pioneiros da Educação Nova (1932). In: SEMINÁRIO NACIONAL DE ESTUDOS E PESQUISAS “HISTÓRIA, SOCIEDADE E EDUCAÇÃO NO BRASIL”, 8., 2009, Campinas, SP. Resumos. Disponível em: <http://www.histedbr.fe.unicamp.br/acer_histedbr/ seminario/seminario8/_files/GuEVnTfr.pdf > . Acesso em: 12/05/2020.

KAMINSKI, Christiane. Educação a distância: Redescutindo o papel do tutor. Revista intersaberes. Vol.10, n.21, p.561-576. Set. - dez. 2015 Disponível em: ,< https://www. researchgate.net/publication/327559530_Educacao_a_distancia_rediscutindo_o_papel_do_ tutor > Acesso em: 14/06/2020.

LÉLIS, Ú. A. de. A implementação da educação a distância através da oferta de atividades em ambientes virtuais de aprendizagem, em cursos presenciais de licenciatura/Unimontes - 20072008. Monografias do IV Curso de Especialização em Educação Continuada e a Distância. Tecnologias em educação. Brasília: UnB, 2011. 
MARTINS, O. B. Sistemas de Gestão EaD: os desafios de uma proposta crítica comprometida com a gestão em EaD. Revista Latinoamericana de Tecnologia Educativa RELATEC. 2010. Disponível em: <https://relatec.unex.es/article/download/631/459/> Acesso em 12/06/2020.

MARCONI, M. A; LAKATOS, E. M. Técnicas de pesquisa: planejamento em execução de pesquisas, amostragens e técnicas de pesquisas, elaboração e interpretação de dados. 3.ed. Atlas, São Paulo 1996.

MENDONÇA, Bruno. Tutor EAD e o seu papel na educação a distância. 2016. Disponível em: <https://www.edools.com/tutor-ead/>. Acesso em: 04 jun. 2019.

MUNHOZ, Antonio Siemsen. Tutoria em EAD: uma nova visäo. Curitiba: InterSaberes, 2014.

PACHECO, Felipe at al. A importância do tutor em ambientes de ensino aprendizagem e ferramentas de avaliação em EaD. Comunicação \& Mercado/ UNIGRAN - Dourados - MS, vol. 04, n.10, p.142-150, jul-dez 2015.

OLIVEIRA, Ana M. A. Passos de. O papel do tutor em cursos de educação a distância: competências e habilidades. Artigo. Revista Multitexto, 2013, v.2, n.01.

SILVA JÚNIOR, Josué Barreto da et al. Educação a distância: desafio e perspectivas. Educaçáo Pública, Rio de Janeiro, v. 15, n. 23, p.1-8, 24 nov. 2015. Mensal. Disponível em: <https:// educacaopublica.cecierj.edu.br/artigos/15/23/educao-a-distncia-desafio-e-perspectivas $>$. Acesso em: 15/04/2020. 